\title{
Testování mechanických vlastností Inconelu 713 a 738 pro pokročilé reaktory
}

\section{Testing of mechanical properties of 713 and 738 inconels for advanced reactors}

\author{
Daniela Marušákovál,2, Jan Berka ${ }^{1,2}$, Petr Sajdl ${ }^{1}$ \\ ${ }^{1}$ Ústav energetiky, VŠCHT Praha \\ ${ }^{2}$ Centrum výzkumu Řež, s.r.o. \\ E-mail: marusakd@vscht.cz
}

Mezi kovové konstrukčni materiály pro komponenty pokročilých plynem chlazených reaktorů patři niklové superslitiny Inconel 713 a 738. V rámci projektu aplikovaného výzkumu řšeného na VŠCHT Praha a CV Řež byly testovány mechanické vlastnosti těchto slitin ve výchozím stavu a po expozici vzor$\mathrm{k}$ ů $v$ heliu obsahujicím stopové nečistoty $\left(\mathrm{CO}, \mathrm{H}_{2}, \mathrm{CH}_{4}, \mathrm{H} 2 \mathrm{O}\right)$ při teplotě $900{ }^{\circ} \mathrm{C}$ po dobu 1000 hod. Vzorky testovaných slitin byly vyrobeny: a) z pưvodního litého materiálu (virgin), b) přepracovaného materiálu z výroby (revert 100R) a c) materiálu ziskaného slitím těchto materiálì v poméru 50V/50R. K určeni mechanických vlastností materiálì po expozicich byly provedeny tahové zkoušky a strukturní analýza pomoci SEM. Porovnány byly zmèny vlastností po expozici jednotlivých testovaných slitin i stejné slitiny vyrobené různými postupy. Zatímco mez kluzu a mez pevnosti poklesly u Inconelu 713 jen zlehka, u Inconelu 738 poklesly výraznè. Stav 50V/50R vykazoval lepši mechanické vlastnosti než stav revert 100R.

\section{ÚVOD}

Obsahem tohoto př́spěvku je zhodnocení mechanických vlastností dvou niklových slitin - Inconel 713 a Inconel 738 po tahových zkouškách. Oba tyto materiály se hojně využívají v energetických zařízeních jako konstrukční prvky - lopatky turbíny, výměníky tepla a další komponenty. Moderní reaktory a parní generátory využívají různých pracovních podmínek teplot, tlaků a druhů media. Momentálně zvažované reaktory IV. generace, jako velmi vysoko-teplotní reaktor (V/HTR) a plynem chlazený rychlý reaktor (GFR) budou chlazeny heliem (helium s nečistotami simuluje korozní prostředí V/HTR). Operační teplota $\mathrm{v}$ reaktorech by měla dosahovat hodnot kolem $850^{\circ} \mathrm{C}-1000^{\circ} \mathrm{C}$. Konstrukční prvky reaktoru jsou obecně vystaveny jak vysokým teplotám, tak vysokému tlaku, které mohou způsobit v př́tomnosti
Nickel superalloys Inconel 713 and 738 belong among metallic construction materials used for components of advances gas cooled reactors. The project of applied research solved by the UCT Prague and RC Rež tested mechanical properties of these alloys in the starting phase and after the exposure to helium containing trace pollutants $\left(\mathrm{CO}, \mathrm{H}_{2}, \mathrm{CH}_{4}, \mathrm{H}_{2} \mathrm{O}\right)$ at the temperature of $900^{\circ} \mathrm{C}$ for a period of 1000 hours. The samples of tested alloys were made from: a) the virgin cast material, b) remanufactured material (revert 100R) and c) casting of previous materials in the ratio of 50V/50R. To identify mechanical properties of the materials after exposure, tensile tests and structural analyses by SEM were carried out. The changes of properties after the exposure of tested alloys and the same alloys made in various procedures were compared. While the yield and tensile strengths dropped insignificantly for Inconel 713, the plummeted for Inconel 738. The 50V/50R state showed better mechanical properties than the revert $100 R$ state.

nečistot, solí a vlhkosti korozní praskání pod napětím (SCC), ale především se předpokládá změna struktury materiálu vlivem vysoké teploty a s tím spojenou změnu mechanických vlastností. Proto je velmi důležité zvolit ke konstrukci vysoce teplotně i mechanicky odolný materiál, jako např́klad niklové slitiny - Inconel 713 a 738 [1-6].

\section{Expozice a materiálové zkoušky}

Tahové vzorky byly vyrobeny jako přesné odlitky metodou vytavitelného modelu ze dvou stavů, z obou materiálů. Stav revert $100 \mathrm{R}$ je plně přepracovaný zbylý materiál po prvním lití. Stav 50V/50R se skládá z 50\% virgin stavu a $50 \%$ revert $100 \mathrm{R}$ stavu. Složení virgin stavu je uvedeno v Tabulce 1. 
Tab. 1. Složení slitin IN 713 a IN 738 / Composition of alloys IN 713 and IN 738

\begin{tabular}{|c|c|c|c|c|c|c|c|c|c|c|c|}
\hline Inconel & $\mathbf{C}$ & $\mathbf{C r}$ & $\mathbf{N i}$ & $\mathbf{C o}$ & $\mathbf{M o}$ & $\mathbf{T i}$ & $\mathbf{A l}$ & $\mathbf{W}$ & $\mathbf{T a}$ & $\mathbf{N b}$ & $\mathbf{Z r}$ \\
\hline 713 & 0,05 & 12 & base & 0,5 & 4,5 & 0,7 & 6 & - & - & 2 & 0,01 \\
\hline 738 & 0,11 & 16 & base & 8,5 & 1,75 & 3,45 & 3,45 & 2,6 & 1,75 & 0,85 & 0,035 \\
\hline
\end{tabular}

\section{Expozice $v$ heliu + nečistoty}

Všechny tahové vzorky byly exponovány ve vysokoteplotní peci při teplotě plynu $900^{\circ} \mathrm{C} / 1000 \mathrm{~h}$, při tlaku 4-5 bar. Plyn byl složen z He a nečistot (Tab. 2), který simuluje prostředí chladiva ve VHTR a GFR reaktorech.

Tab. 2. Složení expozičního media při atmosférickém tlaku (HTF křemenná retorta) / Composition of the treatment medium at atmosferic pressure (HTF silicone retort)

\begin{tabular}{|c|c|c|}
\hline Složka & $\begin{array}{c}\text { Koncentrace } \\
{[\mathbf{v p p m}]}\end{array}$ & $\begin{array}{c}\text { Parciální tlak } \\
{[\text { Pa] }}\end{array}$ \\
\hline $\mathrm{CH}_{4}$ & 100 & 10 \\
\hline $\mathrm{CO}$ & 500 & 50 \\
\hline $\mathrm{H}_{2}$ & 100 & 10 \\
\hline Helium & Bal. & Bal. \\
\hline
\end{tabular}

Experimentální zařízení se skládá z trubkové pece, křemenné retorty, plynového potrubí a tlakové lahve. $\mathrm{V}$ jednom plynovém potrubí je obsažen vlhkoměr, který je situován právě před vstupem do pece. Celý tento systém umožňuje detekci vlhkosti od koncentrace 1 ppm $[1,2]$.

\section{Tahové zkoušky}

Po expozici byly provedeny tahové zkoušky na tahovém stroji Instron 1362. Mechanické vlastnosti virgin stavu jsou známy z výroby. Pro IN 713 je mez kluzu
$820 \mathrm{MPa}$ a mez pevnosti $1003 \mathrm{MPa}$. Pro IN $738 \mathrm{je} \mathrm{mez}$ kluzu $833 \mathrm{MPa}$ a mez pevnosti $1099 \mathrm{MPa}$.

Jak je vidět $\mathrm{v}$ Tab. 3 , mechanické vlastnosti stavů revert $100 \mathrm{R}$ a $50 \mathrm{~V} / 50 \mathrm{R}$ jsou vyšší pro In 738 před expozicí, avšak po expozici tyto vlastnosti výrazně klesají. U IN 713 však klesají jen lehce, a obě tyto vlastnosti jsou v závěru po expozici vyšší u IN 713. V porovnání ke stavu materiálu, 50V/50R má vyšší mechanické vlastnosti než stav revert 100R. Celkově nejvyšší hodnoty po expozici má IN 713, stav 50V/50R, jehož mez kluzu se od původního materiálu liší jen v jednotkách MPa a mez pevnosti dokonce vzrostla.

\section{SEM analýza}

SEM analýza byla provedena po tahových zkouškách. K lomu došlo podél struktury dendritů, jak ukazuje Obr. 1 a Obr. 2.

Mezi stavy 50V/50R a revert 100R není patrný žádný významný rozdíl před expozicí - výchozí stav (obrázky nalevo) a je pozorovatelné pouze drobné zhrubnutí dendritické struktury po expozici v heliu (obrázky na pravé straně). Tato dendritická segregace vytváři heterogenní místa v materiálu a iniciuje tak lom. Po zvětšení jsou patrné staženiny podél dendritů, Obr. 3, výrazné staženiny jsou pak především ve středu vzorků, což také iniciuje lom. Tyto staženiny pravděpodobně vznikly během výrobního procesu litím.

Detailní analýza ukázala, že stav revert 100R obsahuje více staženin než stav 50V/50R. Možný je vliv expozice na nárůst objemu těchto staženin $[7,8]$.

Tab. 3. Mez kluzu a mez pevnosti Inconelu 713 a 738, před a po expozici / Yield strength and breaking strength of Inconel 713 and 738 , before and after the exposure

\begin{tabular}{|c|c|c|}
\hline Materiál & Mez kluzu - Rp 0,2 [MPa] & Mez pevnosti - Rm [MPa] \\
\hline IN 713 - 50V/50R - neexponovaný & 829,5 & 936,5 \\
\hline IN 713 - 50V/50R - exponovaný & 708,8 & 867,3 \\
\hline IN 713 - revert 100R - neexponovaný & 796,5 & 931,8 \\
\hline IN 713 - revert 100R - exponovaný & 714,5 & 851,2 \\
\hline IN 738 - 50V/50R - neexponovaný & 862,7 & 986,2 \\
\hline IN 738 - 50V/50R - exponovaný & 691,0 & 864,8 \\
\hline IN 738 - revert 100R - neexponovaný & 835,2 & 976,0 \\
\hline IN 738 - revert 100R - exponovaný & 687,4 & 773,6 \\
\hline
\end{tabular}



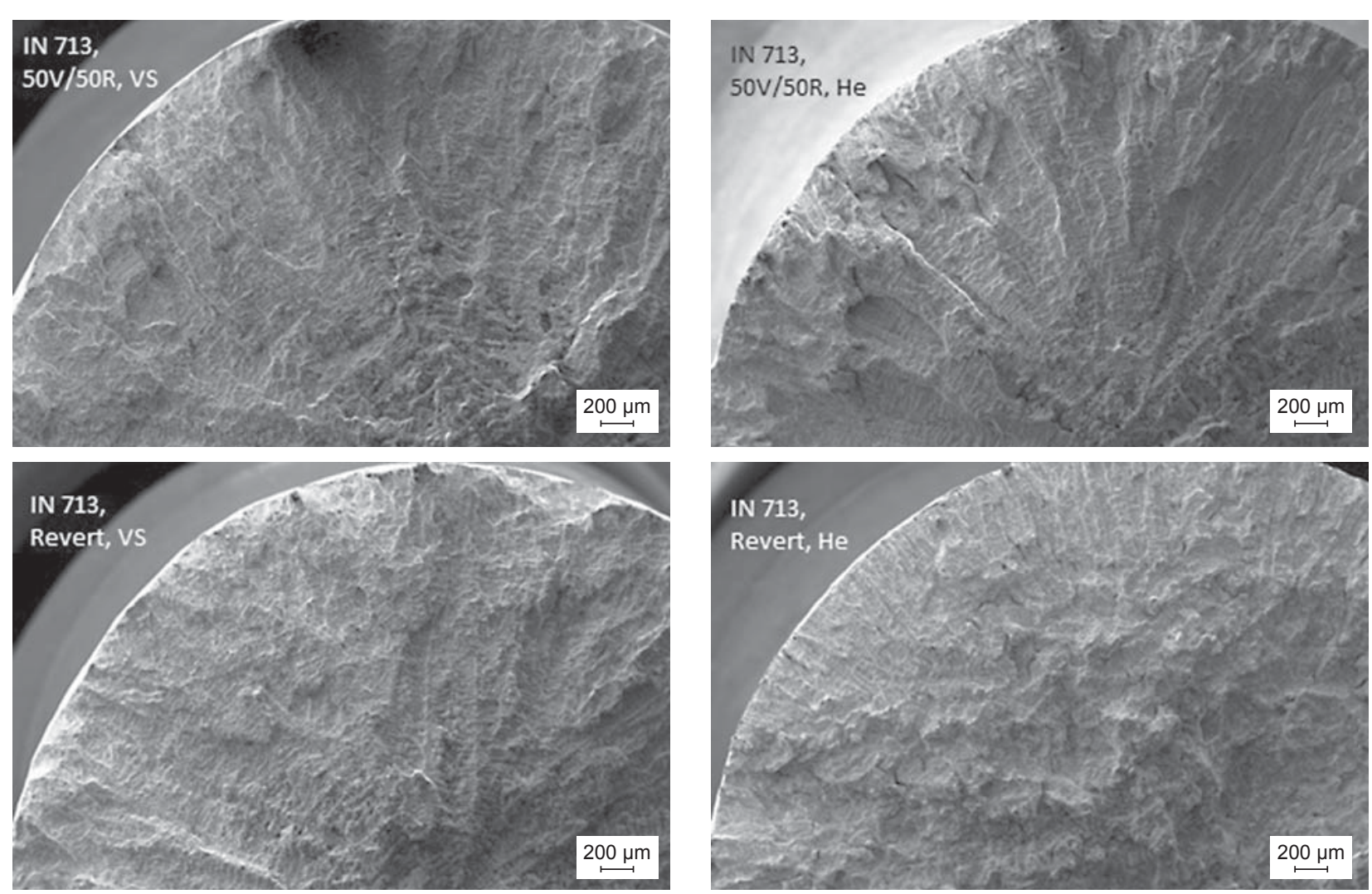

Obr. 1. Lomová plocha IN 713

Fig. 1. Fracture surface of IN 713
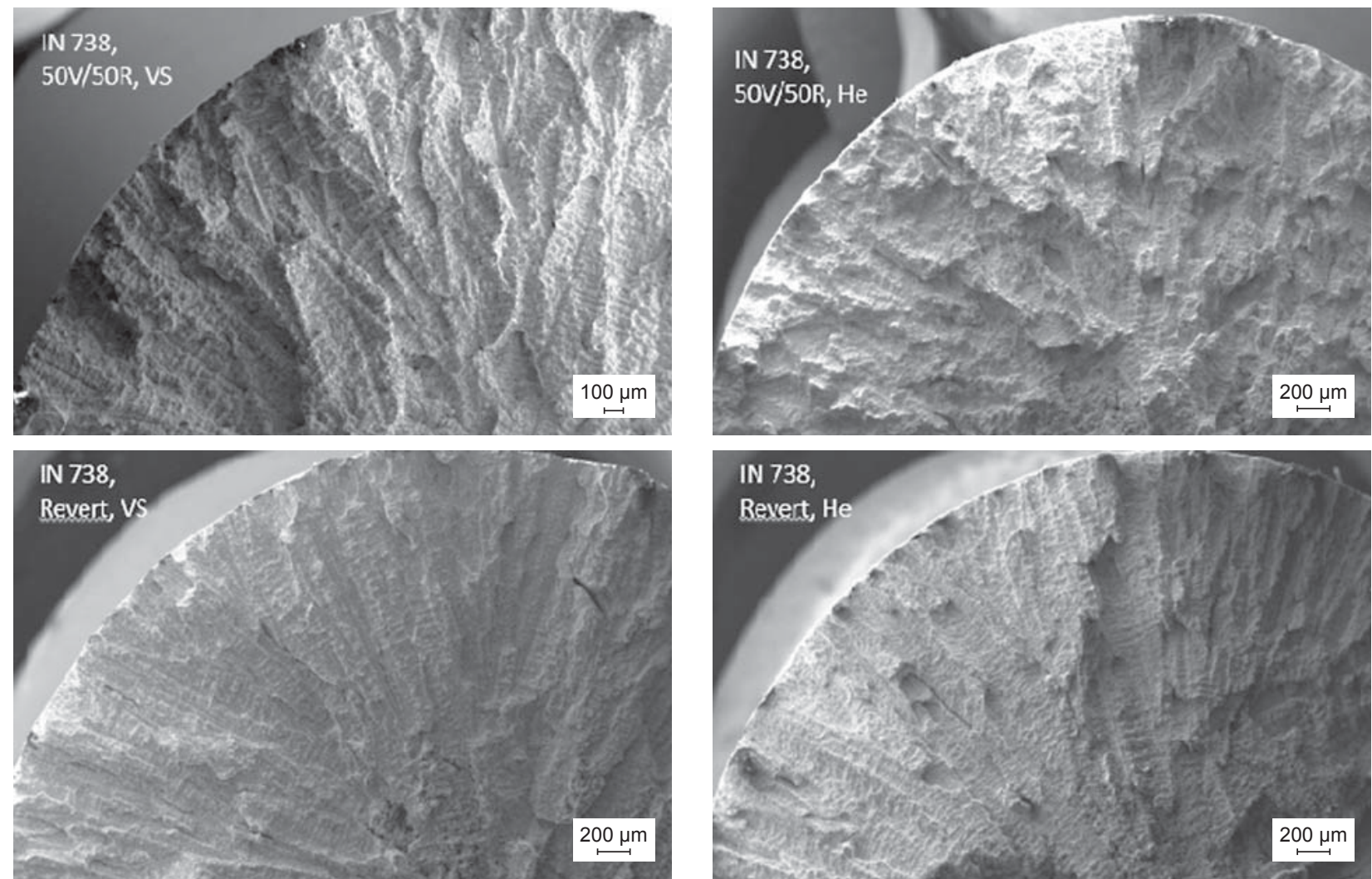

Obr. 2. Lomová plocha IN 738

Fig. 2. Fracture surface of IN 738 

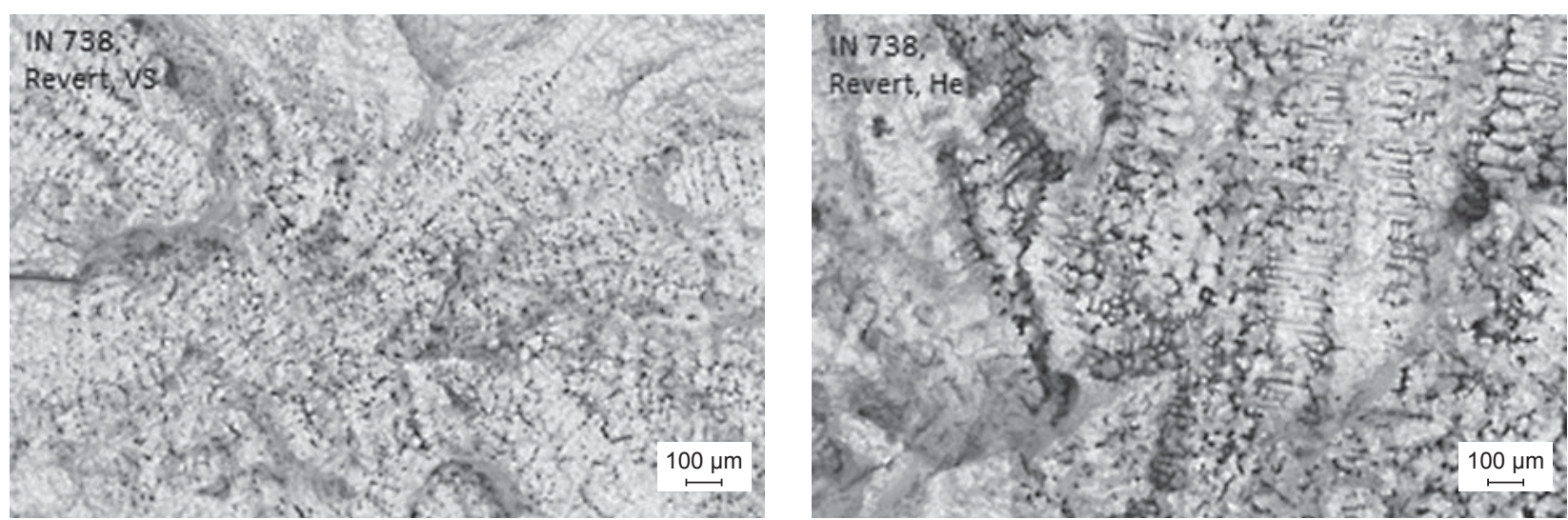

Obr. 3. IN 738, revert - výchozí stav před (vlevo) a po (vpravo) expozici v He (režim zpětně odražených elektronů)

Fig. 3. IN 738, revert - before (left) and after (right) the exposure in He (backscattered electrons mode)

\section{ZÁVĚR A DISKUZE}

Niklové slitiny materiálu IN 713 a IN 738 byly exponovány $\mathrm{v}$ heliu $\mathrm{s}$ nečistotami $-900^{\circ} \mathrm{C} / 1000 \mathrm{~h}$. $\mathrm{Z}$ výsledků po tahových zkouškách bylo zjištěno, že mez kluzu a mez pevnosti poklesly jen zlehka u IN 713 . Oproti tomu u IN 738 poklesy tyto hodnoty významně, což ukazuje vyšší vliv expozice na vlastnosti tohoto materiálu. V porovnání ke stavům lití: stav 50V/50R vykazuje vyšší mechanické vlastnosti než stav revert 100R. SEM analýza prokázala lom materiálu po dendritické struktuře $\mathrm{s}$ částečnou iniciací ve staženinách ve středu vzorků, které zrrejmě vlivem expozice nabyly na objemu. Nejobjemnější staženiny pak byly pozorovány u stavu revert 100R po expozici.

\section{Poděkování}

Práce byla podporována specifickým vysokoškolským výzkumem (MSMT No 20/2015), IGS VSCHT 218 88 1504, ve spolupráci s Monikou Vilémovou z Ústavu fyziky plazmatu AV ČR, v.v.i.

Tato práce vznikla za finanční podpory projektu SUSEN CZ.1.05/2.1.00/03.0108, který je realizován v rámci Evropského fondu regionálního rozvoje (ERDF).
Př́spěvek je součástí projektu TAČR - Alfa projekt TA03010849.

\section{LITERATURA}

1. Berka, J., Hlinčík, T., Víden, I., Hudský, T., Vít, J. Progress in Nuclear Energy 2015, 85, 156-163.

2. Berka, J., Matěcha, J., Černý, M., Víden, I., Sus, F., Hájek, P. Nuclear Engineering and Design 2012, 251, 203-207.

3. Natesan K., Purohit, A., Tam S. W.: report NUREG/CR6824: Materials Behavior in HTGR Environments 2003, Office of Nuclear Regulatory Research, Washington.

4. Yun, M. H., Ennis, J. P., Nickel, H., Schuster, H. Journal of Nuclear Materials 1984, 125, 258-272

5. Graham, W. L. Journal of Nuclear Materials 1990, 171, 76-83.

6. Cabet, C., Duprey, B. Nuclear Engineering and Design 2012, 251, 139-145.

7. Řičánková, V., Němec K.: The image analyses utilization at nickel-base superalloy degradation classification 2008, Diploma thesis, Brno.

8. Otáhal V.: Vady odlitků, atlas vad: železné a neželezné slitiny, MetalCasting and Foundry Conslut, Brno. 